\title{
A Prospective Study of Prenatal and Childhood Lead Exposure and Erythropoietin Production
}

\author{
Joseph Graziano, PhD \\ Vesna Slavkovich, MS \\ XinHua Liu, PhD \\ Pam Factor-Litvak, PhD \\ Andrew Todd, PhD
}

\section{Learning Objectives}

- Summarize what previous studies have shown about the association of blood lead $(\mathrm{BPb})$ concentration, hemoglobin $(\mathrm{Hgb})$, and erythropoietin (EPO) production.

- Compare levels of Pb in blood and tibial bone, hemoglobin levels, and EPO production in lead-exposed and unexposed children 4.5 to 12 years of age.

- Identify the likely underlying cause of these findings and their implications for lead-exposed children.

\section{Abstract}

We test the hypothesis that chronic lead $(\mathrm{Pb})$ exposure may be associated with an inability to maintain an adequate serum erythropoietin (EPO) concentration. From a longitudinal study of $\mathrm{Pb}$ exposure and infant and childhood development, we measured blood $\mathrm{Pb}(\mathrm{BPb})$ and serum EPO concentrations serially at ages 4.5, 6.5, 9.5, and 12 and tibia (cortical) $\mathrm{Pb}$ concentration at age 12. Pb-exposed children aged 4.5 and 6.5 produced increased concentrations of EPO to maintain normal Hgb concentrations. EPO production declined between ages 4.5 and 6.5. At ages 9.5 and 12, further diminution of the association was found. No association was found between tibia $\mathrm{Pb}$ and EPO. The continued decline in the slope of the relationship between $E P O$ and $\mathrm{BPb}$ with age, after adjustment for hemoglobin, implies a gradually decreasing capacity to produce EPO (J Occup Environ Med. 2004;46:924-929)

From the Department of Environmental Health Sciences (Drs Graziano, Slavkovich, Factor-Litvak), Department of Biostatistics (Dr Liu), and Department of Epidemiology, Mailman School of Public Health, Columbia University (Dr Factor-Litvak); and Department of Community and Preventive Medicine, Mount Sinai School of Medicine (Dr Todd), New York, New York.

Supported by grants ES03460, P30 ES09089, ES06616, and ES05697 from the National Institute of Environmental Health Sciences.

Joseph Graziano has no commercial interests related to this article.

Address correspondence to: Joseph Graziano, PhD, Department of Environmental Health Sciences, Mailman School of Public Health, 60 Haven Avenue, New York, NY 10032; E-mail address: jg24@columbia.edu.

Copyright (C) by American College of Occupational and Environmental Medicine

DOI: 10.1097/01.jom.0000137721.95544.4f igh dose-environmental lead $(\mathrm{Pb})$ exposure is associated with anemia, ${ }^{1-3}$ the mechanisms of which are not totally clear. It is known that $\mathrm{Pb}$ exposure is associated with impaired heme synthesis, ${ }^{4-6}$ but even very high blood lead concentrations $(\mathrm{BPb})$ cannot account for the full decrement in hemoglobin $(\mathrm{Hgb})$ synthesis. ${ }^{5} \mathrm{~Pb}$ has other effects on erythrocytes, including inhibition of pyrimidine$5^{\prime}$-nucleotidase activity, ${ }^{7}$ ineffective erythropoiesis, ${ }^{8}$ and shortened red cell survival, ${ }^{9-10}$ but taken together, these still do not account for the effects on $\mathrm{Hgb}$ concentration.

Our interest in the mechanism of $\mathrm{Pb}$-induced anemia was sparked by a report by Grandjean et al, ${ }^{11}$ who described delayed blood regeneration capacity in $\mathrm{Pb}$-exposed workers who had normal Hgb concentrations prior to donation of a unit of blood. We hypothesized that $\mathrm{Pb}$ may inhibit the production of erythropoietin (EPO), a glycoprotein hormone that regulates both steady-state and accelerated erythrocyte production. More than $90 \%$ of EPO is produced in the proximal tubule of the kidney, the site of substantial $\mathrm{Pb}$ accumulation.

Using data from a long-term prospective study of environmental $\mathrm{Pb}$ exposure in pregnant women and their offspring, ${ }^{12-14}$ we previously examined the relationships between $\mathrm{BPb}$ and $\mathrm{EPO}$ during pregnancy and in children at ages $4.5,6.5$, and 9.5 years. In pregnant women, EPO was significantly depressed among those with moderately elevated BPbs. ${ }^{15}$ Further, we found that children with 
elevated $\mathrm{BPb}$ maintained normal $\mathrm{Hgb}$ values, but required hyperproduction of EPO to do so. ${ }^{16} \mathrm{We}$ hypothesized that children with moderately elevated $\mathrm{BPb}$ have shortened red cell survival, a phenomenon previously described in children with $\mathrm{Pb}$ encephalopathy ${ }^{9}$ and in $\mathrm{Pb}$ workers. ${ }^{10}$ Here, we extend our observation of the same cohort of children and examine the associations between $\mathrm{Pb}$ exposure during childhood and EPO concentrations up to age 12. We previously reported relationships between $\mathrm{BPb}$ and EPO through age 9.5. The skeleton is the largest reservoir of $\mathrm{Pb}$ in the body, and the half-life of $\mathrm{Pb}$ in bone is of the order of years. Thus, bone $\mathrm{Pb}$ is believed to be the best surrogate of lifetime exposure. ${ }^{17-19}$ The current analyses are unique in that cumulative $\mathrm{Pb}$ exposure is assessed using both average $\mathrm{BPb}$ from birth through age 12 , and tibial bone lead concentrations measured at age 12 .

\section{Methods}

This study was conducted in two towns in Kosovo, Yugoslavia: Kosovska Mitrovica (K. Mitrovica), the site of a $\mathrm{Pb}$ mine, smelter, refinery, and battery plant; and Pristina, a relatively unexposed town 25 miles to the south. Children were selected for follow-up from a previous prospective study of 1502 pregnant women residing in these towns. Pregnancy outcomes ${ }^{20}$ and childhood developmental outcomes have been previously described. ${ }^{13-15}$ Field work was completed in December 1998 , months before the outbreak of war in Kosovo.

\section{Subjects}

In brief, 706 mother-infant pairs from the pregnancy study were invited to participate in a follow-up study involving repeated visits at 6-month intervals. Of these, the parents of 541 consented and brought their children to at least one visit. Of those who consented, 311 (53.5\%), $267(49.4 \%), 260(48.1 \%)$, and 280 $(51.8 \%)$ participated in the visits at ages 4.5, 6.5, 9.5, and 12 years, respectively. For the present study, whole blood for $\mathrm{BPb}$ and $\mathrm{Hgb}$ were available for 272, 201, 234, and 280 children at each of these ages, respectively; sera for EPO analyses were available for $211,178,234$, and 280 children, respectively.

In December, 1998, we measured tibia lead (Tib- $\mathrm{Pb})$ in cohort participants between the ages of 11 and 13 . Logistical and cost constraints limited the number of children in whom we could measure bone $\mathrm{Pb}$. We therefore selected a subsample of the cohort with a broad range of $\mathrm{Pb}$ exposures from among those with eight or more serial $\mathrm{BPb}$ measurements. This subsample included 209 children: 111 in K. Mitrovica and 98 in Pristina. Blood samples were obtained on 280 children: 49 children at age $11(17.5 \%), 91$ children at age $11.5(32.5 \%), 107$ children at age 12 $(38.2 \%), 32$ children at age 12.5 $(11.4 \%)$, and 1 child at age 13.5 $(0.3 \%)$. The mean $( \pm$ standard deviation, SD) age of the children was $11.72( \pm 0.47)$ years.

\section{Laboratory Analyses}

At mid-pregnancy, delivery and at each 6-month follow-up visit, venous blood samples were taken for the measurement of $\mathrm{BPb},{ }^{21}$ erythrocyte protoporphyrin (EP), ${ }^{22}$ and $\mathrm{Hgb}$. At each visit, additional sera were obtained and frozen immediately to create a serum bank, from which the current study is derived. Whole blood and serum samples were stored at $4^{\circ} \mathrm{C}$ and $-20^{\circ} \mathrm{C}$, respectively, and appropriately transported to Columbia University, where all assays were performed. The laboratory participates in the $\mathrm{BPb}$ and $\mathrm{EP}$ quality control program of the Centers for Disease Control and Prevention. During the study period relevant to this analysis, agreements with the quality control values for $\mathrm{BPb}$ and EP, measured by intraclass correlation coefficients, were both 0.99 .

All available sera from the visits at ages $4.5,6.5,9.5$, and 12 years were analyzed in duplicate for EPO using a commercially available enzyme immunoassay. ${ }^{23}$ In our laboratory, the limit of detection of the assay was $0.6 \mathrm{mIU} / \mathrm{mL}$, and the coefficients of variation for duplicate measures was $9.8 \%, 8.3 \%, 7.9 \%$, and $3.3 \%$, respectively, at ages $4.5,6.5$, 9.5 , and 12 years.

\section{Bone Lead}

Tibia bone lead (Tib-Pb) was measured using ${ }^{109} \mathrm{Cd}$-based K-shell-x-ray fluorescence, ${ }^{24}$ details of the technology used in the current study have been previously described. ${ }^{25}$ Measurement uncertainty with this procedure, which uses previous-generation spectroscopy electronics, in children is similar to that in adults. With our instrumentation, the minimum-detectable Tib- $\mathrm{Pb}$ was $4 \mu \mathrm{g} \mathrm{Pb} / \mathrm{g}$ bone mineral (ie, three times the standard deviation of repeated measures of a blank sample). For $\mathrm{Tib}-\mathrm{Pb}$ that measured close to or less than this limit, the instrumentation occasionally recorded negative values. This results from production of an unbiased point estimate of Tib- $\mathrm{Pb}$ that oscillates around the true $\mathrm{Tib}-\mathrm{Pb}$ value. In the present sample, Tib- $\mathrm{Pb}$ measurements ranged between -14.4 and $+193.5 \mu \mathrm{g} \mathrm{Pb} / \mathrm{g}$ bone mineral. Previous investigations of the use of negative values of Tib$\mathrm{Pb}^{26,27}$ suggest that their retention in analyses is useful because alternative procedures, such as recoding them to " 0 " or to a multiple of the standard deviation of the background noise, introduce bias. We performed our analysis twice, once retaining the negative values and once adding a constant of 15 to eliminate negative values when the logarithmic transformation was used; this transformation was undertaken to make the distributions approximately symmetrical. Results from both analyses were comparable, and we report analyses using the latter algorithm.

\section{Statistical Analysis}

The association between $\mathrm{BPb}$ and EPO was examined using regression methods. Because the distributions of $\mathrm{EPO}$ and $\mathrm{BPb}$ are skewed, loga- 
rithmic transformations were used for these variables. All analyses were performed using SAS version 6.12 or 8.1 (SAS Institute, Cary, NC). First, we evaluated the association between $\mathrm{BPb}$ and EPO at each age using linear regression analysis, controlling for concurrent $\mathrm{Hgb}$ concentration. Concurrent $\mathrm{Hgb}$ was always controlled because it is the most important predictor of EPO. ${ }^{15,16} \mathrm{Sec}-$ ond, we combined data from all ages and used repeated measures analysis to determine whether the associations between $\mathrm{BPb}$ and $\mathrm{EPO}$, controlling for $\mathrm{Hgb}$, changed over time. Third, we estimated cumulative $\mathrm{BPb}$ using the algorithm described below. Finally, we repeated the analyses using Tib- $\mathrm{Pb}$ as the cumulative exposure variable.

The repeated measures models were fitted using the marginal generalized estimating equations approach, ${ }^{28}$ which allows for independent effects of age and $\mathrm{BPb}$ at each age on EPO at each age while controlling for the within-subject correlations. In all, 875 observations from 373 subjects with $\mathrm{EPO}, \mathrm{BPb}$ and $\mathrm{Hgb}$ measures were available for this analysis. The 875 observations included $101(27.1 \%)$ subjects who had one measure, $111(29.8 \%)$ who had two, 92 (24.7\%) who had three, and $69(18.5 \%)$ who had all four EPO measures.

Cumulative lifetime exposure to $\mathrm{Pb}$ was first estimated using the average of $\mathrm{BPb}$ measurements obtained at 6-month intervals from birth until age 12 . The distribution of $\mathrm{BPb}$ is skewed; we therefore used a base 10 logarithmic transformation. Because $\mathrm{BPbs}$ measured serially in this population are highly correlated, ${ }^{13}$ for children missing measurements we estimated the cumulative lifetime average $\mathrm{BPb}$ using all available data.

For subjects with missing values for $\mathrm{BPb}$ or $\mathrm{Hgb}$ at a specific time point, we used the following algorithm to substitute values. If $\mathrm{BPb}$ (or $\mathrm{Hgb}$ ) measurements were available for both the 6 months prior to and the 6 months after the missing values, we substituted the mean of these measures. If $\mathrm{BPb}$ (or $\mathrm{Hgb}$ ) was available for only one of these time points, that value was substituted.

\section{Results}

Mean $\mathrm{BPb}, \mathrm{Hgb}$, and EPO data are presented in Table 1 as functions of age and town of residence. As expected, BPbs were substantially higher in K. Mitrovica than Pristina, and BPbs declined somewhat with age. Mean Hgb concentrations remained constant and within the normal range.
Mean EPOs were significantly different between towns at ages 4.5 and 6.5 but not at ages 9.5 or 12 .

$\mathrm{Hgb}$ concentration is the strongest determinant of EPO. We therefore examined EPO concentrations within strata of Hgb (Fig. 1). As expected, children with higher Hgb had lower EPO concentrations. Relatively few children were anemic. For example, at age 4.5 years, $3.3 \%$ had $\mathrm{Hgb}$ $<11.0 \mathrm{~g} / \mathrm{dL}$ at ages; at ages $6.5,9.5$, and 12 , less than $0.5 \%$ of the children had $\mathrm{Hgb}<11.0 \mathrm{~g} / \mathrm{dL}$. Within each Hgb stratum, EPO was significantly higher in K. Mitrovica than in Pristina at ages 4.5 and 6.5, and similar to that in Pristina for ages 9.5 and 12.

As expected, Hgb was always inversely and significantly associated with EPO (data not shown). Associations between $\mathrm{BPb}$ and $\mathrm{EPO}$, adjusted for $\mathrm{Hgb}$ and specific to each age, are shown in Table 2. Statistically significant associations were found between $\mathrm{BPb}$ and $\mathrm{EPO}$ at ages 4.5 and 6.5 , although the magnitude of the association at the latter age was greatly reduced with age. At ages 9.5 and $12, \mathrm{BPb}$ was no longer significantly associated with EPO and the magnitudes of the associations continued to decline.

TABLE 1

Hematological Parameters for 280 Children in Kosovska Mitrovica and Pristina, Yugoslavia, at Ages 4.5, 6.5, 9.5, and 12 Years

\begin{tabular}{|c|c|c|c|c|c|}
\hline \multirow[b]{3}{*}{ Parameter } & \multirow[b]{3}{*}{ Age } & \multicolumn{4}{|c|}{ Town } \\
\hline & & \multicolumn{2}{|c|}{ K. Mitrovica } & \multicolumn{2}{|c|}{ Pristina } \\
\hline & & Mean & SE* $^{*}$ & Mean & $\mathrm{SE}^{*}$ \\
\hline \multirow{3}{*}{ Blood lead concentration ( $\mu \mathrm{g} / \mathrm{dL})$} & 6.5 & 36.2 & 1.15 & 8.1 & 0.35 \\
\hline & 9.5 & 28.1 & 0.92 & 6.6 & 0.22 \\
\hline & 12 & 30.6 & 0.84 & 6.1 & 0.17 \\
\hline \multirow{2}{*}{ Hemoglobin concentration (g/dL) } & 9.5 & 12.9 & 0.063 & 13.0 & 0.075 \\
\hline & 12 & 12.9 & 0.071 & 12.9 & 0.072 \\
\hline \multirow[t]{4}{*}{ Erythropoietin concentration (mlU/mL) } & 4.5 & 7.8 & 0.73 & 5.6 & 0.32 \\
\hline & 6.5 & 9.7 & 0.43 & 8.2 & 0.46 \\
\hline & 9.5 & 8.8 & 0.35 & 8.8 & 0.59 \\
\hline & 12 & 9.6 & 0.40 & 9.2 & 0.35 \\
\hline
\end{tabular}

\footnotetext{
${ }^{*}$ Standard error of the mean.
} 

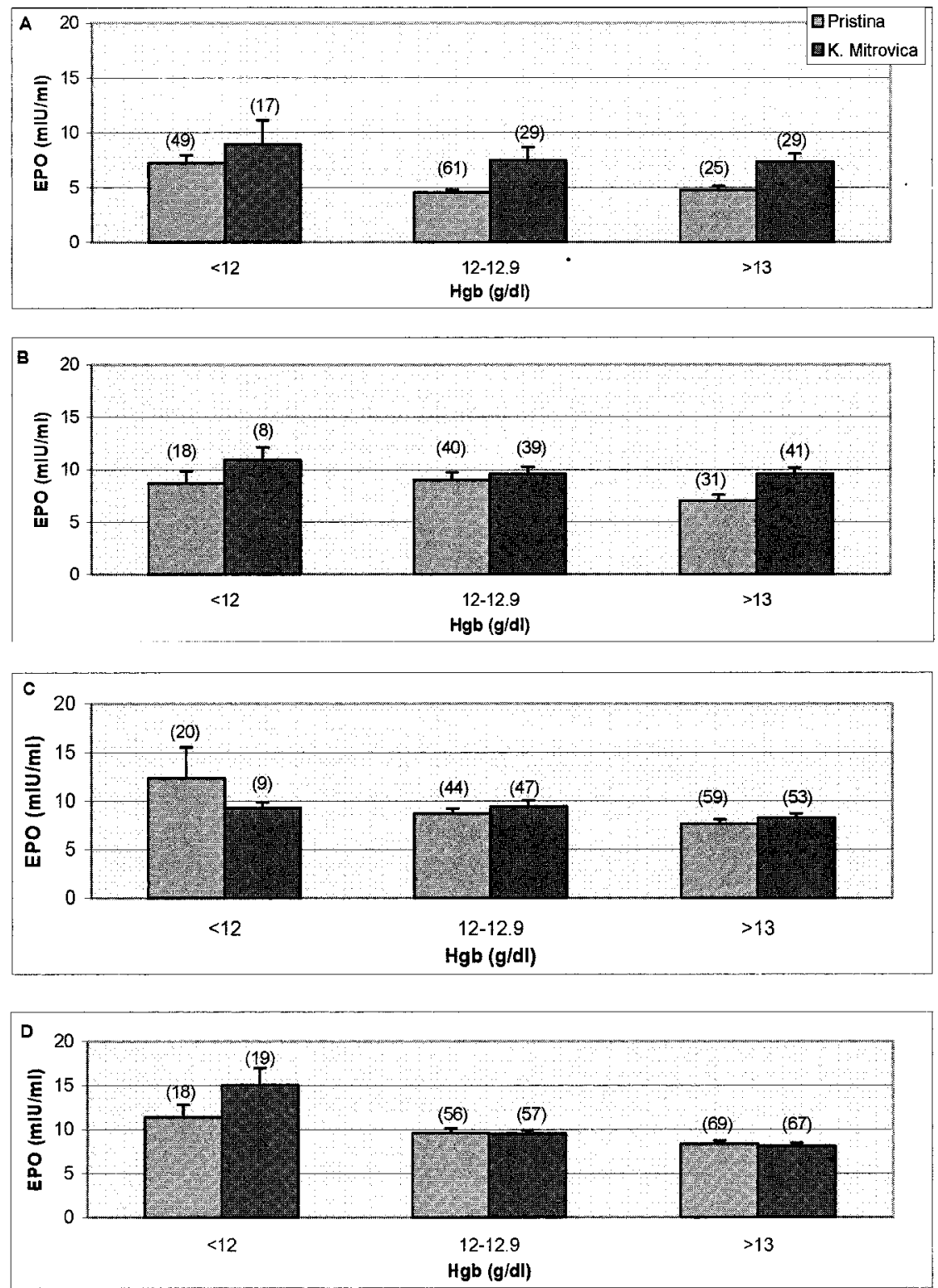

Fig. 1. Mean serum EPO concentrations in children in Kosovska Mitrovica and Pristina, Yugoslavia, stratified by hemoglobin concentration. At ages 4.5 (A) and 6.5 (B) children in K. Mitrovica had significantly higher serum EPO. At ages 9.5 (C) and 12 (D), serum EPO concentrations were comparable. Error bars indicate standard errors. Numbers in parentheses indicate number of children each bar represents.

Results of the repeated measures analysis confirmed these findings. At ages 4.5 and 6.5, after adjustment for $\mathrm{Hgb}, \mathrm{BPb}$ was positively and significantly associated with EPO $(P<$ 0.0001 and $P=0.0007$, respectively). This association diminished at ages 9.5 and $12(P>0.10)$. To test whether the association between $\mathrm{BPb}$ and EPO varied by age, we repeated all analyses, including the appropriate interaction terms. Based on this model, a significant interaction between $\mathrm{BPb}$ and age was found, indicating that the association changed with age. As shown in Fig. 2, the slopes of the regression lines declined in a clockwise rotation with age. We found no significant interactions between $\mathrm{Hgb}$ and age. Neither $\mathrm{Tib}-\mathrm{Pb}$ nor average cumulative lifetime $\mathrm{BPb}$ was associated with EPO measured at age 12. Furthermore, there was no evidence of non-
TABLE 2

Regression Coefficients Relating Blood Lead Concentration to Serum Erythropoietin Concentration for All Children 4.5, 6.5, 9.5, and 12 Years of Age

\begin{tabular}{llll}
\multicolumn{1}{c}{ Age (Years) } & \multicolumn{1}{c}{ B $^{*}$} & SE† & $\boldsymbol{P}$ Value \\
\hline 4.5 & 0.21 & 0.043 & 0.0001 \\
6.5 & 0.11 & 0.041 & 0.0103 \\
9.5 & 0.029 & 0.033 & 0.39 \\
12 & 0.016 & 0.031 & 0.60 \\
Average to age 12† & 0.022 & 0.034 & 0.51 \\
Bone $\mathrm{Pb}$ & 0.0089 & 0.033 & 0.79
\end{tabular}

* Estimated regression coefficient.

† Standard error of estimated regression coefficient.

$\ddagger$ Average of all blood lead concentrations through age 12 years.

linear associations between these variables and EPO.

\section{Discussion}

This prospective analysis investigating one mechanism that contributes to $\mathrm{Pb}$-induced anemia builds on our previous work with this cohort. We previously reported that $\mathrm{Pb}$ exposed children aged 4.5 and 6.5 produced increased concentrations of EPO to maintain normal $\mathrm{Hgb}$ concentrations. ${ }^{16}$ However, the degree of EPO hyperproduction declined between ages 4.5 and 6.5. In addition, by age 9.5 , a further diminution of the association was found. Extending these analyses to age 12 , we find even less of an association between $\mathrm{BPb}$ and $\mathrm{EPO}$. Taken with our observations on the pregnant mothers of these children, our current data provides further confidence in the hypothesis that in nonanemic $\mathrm{Pb}$ exposed young children, increased erythrocyte production is required to maintain normal Hgb concentrations. The continued decline in the slope of the relationship between EPO and $\mathrm{BPb}$ with age, after adjustment for $\mathrm{Hgb}$, implies that in children with chronically elevated $\mathrm{BPb}$, the capacity to produce EPO declines over the course of time. This decline is likely the result of cell damage in the proximal renal tubule, the site of EPO production and $\mathrm{Pb}$ toxicity. 


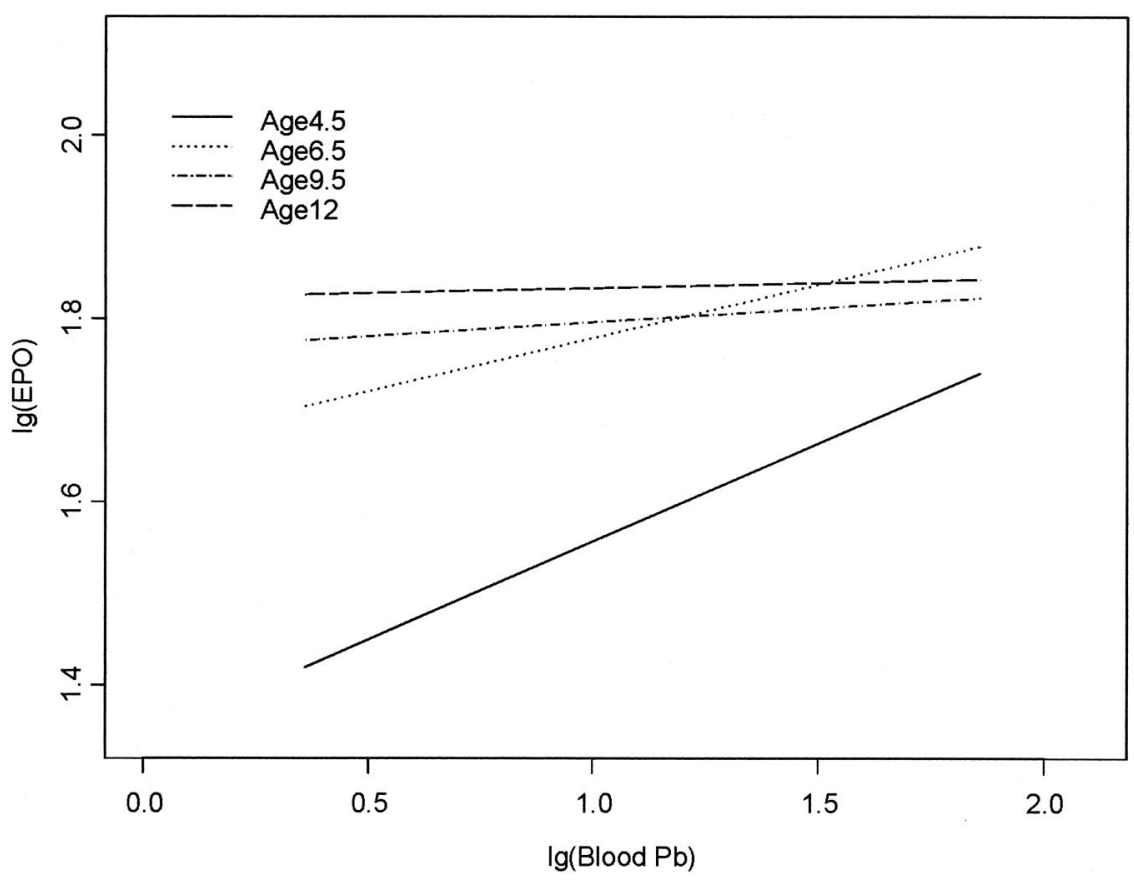

Fig. 2. Relationships between $\log (\mathrm{BPb})$ and $\log (\mathrm{EPO})$, adjusted for $\mathrm{Hgb}$, at ages 4.5, 6.5, 9.5, and 12 years in children in Kosovska Mitrovica and Pristina, Yugoslavia.

To our knowledge, this is the first study to measure serum EPO longitudinally in children between the ages of 4.5 and 12 years. In Pristina, ie, the relatively low-exposure town, we observed a gradual increase in serum EPO, from $5.6 \mathrm{mU} / \mathrm{mL}$ at age 4.5 to $9.2 \mathrm{mU} / \mathrm{mL}$ at age 12 . This trend was not as clear in $\mathrm{K}$. Mitrovica. We note that, in our laboratory, nonanemic pregnant women from Pristina (mean $\mathrm{BPb} 3.6 \mu \mathrm{g} / \mathrm{dL}$ ) had a mean serum EPO of $9.8 \mathrm{mU} /$ $\mathrm{mL},{ }^{15}$ roughly comparable with the children at age 12. Thus, it appears that serum EPO undergoes a gradual increase during childhood in the face of unchanging $\mathrm{Hgb}$ concentrations (Table 1). The reason for this rise is not apparent.

There is substantial evidence to suggest that the hyperproduction of $\mathrm{EPO}$ in $\mathrm{Pb}$ exposed young children is a response to $\mathrm{Pb}$-induced shortened red cell survival. As early as 1925, a review by Aub et $\mathrm{al}^{1}$ described the anemia of $\mathrm{Pb}$ poisoning as one that occurs in two phases. Initially, accelerated erythrocyte destruction is responsible for a fall in Hgb concentration. Animal studies revealed that during this phase, splenectomy could reverse the anemia, presumably by lengthening red cell survival. In rabbits with acute $\mathrm{Pb}$ poisoning, peripheral red cell destruction was followed by bone marrow hyperplasia, undoubtedly caused (in hindsight) by increased EPO production. Over the course of time, however, anemia and bone marrow hypoplasia ensued, suggesting either failure of the erythropoietic stem cells, a decline in EPO production, or both. Leikin and Eng ${ }^{9}$ found a similar progression in children with $\mathrm{BPbs}$ ranging from 60 to $238 \mu \mathrm{g} / \mathrm{dL}$.

More recent data find stronger associations between cumulative $\mathrm{Pb}$ exposure and $\mathrm{Hgb}$. Hu et $\mathrm{al}^{29}$ found a significant association between tibia (and patella) bone $\mathrm{Pb}$ and $\mathrm{Hgb}$ among nonanemic male carpenters but not association between $\mathrm{BPb}$ and Hgb. The authors suggest that these observations reflect the inhibition of erythropoiesis through reduced EPO synthesis, with bone $\mathrm{Pb}$ serving as a proxy for renal $\mathrm{Pb}$ accumulation. Among long-term $\mathrm{Pb}$ workers, EPO concentrations were significantly lower among those with $\mathrm{BPbs}>30$ $\mu \mathrm{g} / \mathrm{dL}$ than among those with BPbs less than $20 \mu \mathrm{g} / \mathrm{dL} .^{30,31} \mathrm{We}$ do not find an association between Tib- $\mathrm{Pb}$ and $\mathrm{Hgb}$ (data not shown), nor do we find an association between Tib- $\mathrm{Pb}$ and EPO in our children. This may be the result of a gradual decline in the ability to produce EPO, which is not clinically significant at age 12 . In an analysis of the pregnant mothers of these children, ${ }^{15}$ we found a significant inverse association between $\mathrm{BPb}$ and EPO. We note that the mothers were exposed to high airborne $\mathrm{Pb}$ for most, if not all, of their lives.

Somewhat contrary to our findings, Liebelt et $\mathrm{al}^{32}$ found decreased EPO concentrations with increasing $\mathrm{BPb}$ among 86 children between ages 1 and 6 years (mean age 34 months). These children were recruited from either a university based $\mathrm{Pb}$ clinic or a primary care clinic. Mean $\mathrm{BPb}$ in this population was 18 $\mu \mathrm{g} / \mathrm{dL}$ (range 2 to $84 \mu \mathrm{g} / \mathrm{dL}$ ) and mean EPO was $5.9 \mathrm{mIU} / \mathrm{mL}$ (range 2.3 to $11.5 \mathrm{mIU} / \mathrm{mL}$ ). The difference in results, in part, may be the result of confounding by age in their study.

In summary, the Yugoslavia Prospective Cohort Study of $\mathrm{Pb}$ has provided a unique opportunity to assess the relationships between $\mathrm{Pb}$ exposure and EPO in a population well characterized from birth onward. Collectively, our studies of EPO in this cohort indicate that the spectrum of nephrotoxicity of $\mathrm{Pb}$ includes a gradual decline in EPO production.

\section{References}

1. Aub JC, Fairhall LT, Monot AS, Reznikoff P. Lead poisoning. Medicine. 1925; 4:1-250.

2. Baker EL Jr, Landrigan PJ, Barbour AG, et al. Occupational lead poisoning in the United States: clinical and biochemical findings related to blood lead levels. $\mathrm{Br} J$ Ind Med. 1979;36:314-322.

3. Schwartz J, Landrigan PJ, Baker EL Jr, Orenstein WA, von Lindern IH. Leadinduced anemia: dose-response relationships and evidence for a threshold. Am J Public Health. 1990;80:169-172.

4. Lichtman HC, Feldman F. In vitro pyrrol 
and porphyrin synthesis in lead poisoning and iron deficiency. J Clin Invest. 1963; 42:830-839.

5. Piomelli S, Lamola AA, Poh-Fitzpatrick MB, Seaman C, Harber LC. Erythropoietic protoporphyria and lead intoxication: the molecular basis for difference in cutaneous photosensitivity. I. Different rates of disappearance of protoporphyrin from the erythrocytes, both in vivo and in vitro. J Clin Invest. 1975;56:1519-1527.

6. Piomelli S, Seaman C, Zullow D, Curran A, Davidow B. Threshold for lead damage to heme synthesis in urban children. Proc Natl Acad Sci USA. 1982;79:33353339.

7. Paglia DE, Valentine WN, Dahlgren JG. Effects of low level lead exposure on pyramidine-5'-nucleosidase and other erythrocyte enzymes. Possible role of pyramidine- 5 '-nucleosidase in the pathogenesis of lead-induced anemia. J Clin Invest. 1975;56:1164-1169.

8. Berk PD, Tschudy DP, Shepley LA, Waggoner JG, Berlin NI. Hematologic and biochemical studies in a case of lead poisoning. Am J Med. 1970;48:137-144.

9. Leikin S, Eng G. Erythrokinetic studies of the anemia of lead poisoning. Pediatrics. 1963;31:996-1002.

10. Hernberg S, Nurminen M, Hasan J. Nonrandom shortening of red cell survival times in men exposed to lead. Environ Res. 1967;1:247-261.

11. Grandjean P, Jensen BM, Sando SH, Jogensen PJ, Antonsen S. Delayed blood regeneration in lead exposure: an effect on reserve capacity. Am J Public Health. 1989;79:1385-1388.

12. Graziano JG, Popovac D, Factor-Litvak P, Shrout P, Kline J, Murphy MJ, et al. Determinants of elevated blood lead during pregnancy in a population surrounding a lead smelter in Kosovo, Yugoslavia. Environ Health Perspect. 1990;89:95100.
13. Factor-Litvak P, Wasserman G, Kline JK, Graziano J. The Yugoslavia prospective study of environmental lead exposure. Environ Health Perspect. 1999;107: 9-15.

14. Wasserman GA, Liu X, Popovac D, et al. The Yugoslavia prospective lead study: contributions of prenatal and postnatal lead exposure to early intelligence. $\mathrm{Neu}$ rotoxicol Teratol. 2000;22:811-818.

15. Graziano JH, Slavkovich V, FactorLitvak P. Depressed serum erythropoietin in pregnant women with elevated blood lead. Arch Environ Health. 1991;46:347350.

16. Factor-Litvak P, Slavkovich V, Liu X, et al. Hyperproduction of erythropoietin in nonanemic lead-exposed children. Environ Health Perspect. 1998;106:361-364.

17. Chettle D. In vivo X-ray fluorescence of lead and other toxic trace elements. In P. Predecki, ed. Advances in X-Ray Analysis New York: Plenum; 1995:563-572.

18. Rabinowitz M, Wetherill G, Kopple J. Kinetic analysis of lead metabolism in healthy humans. J Clin Invest. 1976;58: 260-270.

19. Sommervaille L, Chettle D, Scott M, et al. In vivo tibial lead measurements as an index of cumulative exposure in occupationally exposed subjects. $\mathrm{Br}$ J Ind Med. 1988;45:174-181.

20. Factor-Litvak P, Graziano JH, Kline JK, et al. A prospective study of birthweight and length of gestation in a population surrounding a lead smelter in Kosovo, Yugoslavia. Int J Epidemiol. 1991;20: 722-728.

21. Fernandez F, Hilligoss D. An improved graphite furnace method for the determination of lead in blood using matrix modification and the L'vov platform. Atomic Spectroscophotometry. 1982;3: 130-131.

22. Piomelli S. A micromethod for free erythrocyte porphyrins: the FEP test. J Lab Clin Med. 1973;81:932-940.

23. Quantikine IVD. Human EPO immunoassay (ELISA). \#DEP00. Minneapolis, MN: R\&D Systems; 1987.

24. Todd AC, Chettle DR: In vivo x-ray fluorescence of lead in bone: review and current issues. Environ Health Perspect. 1994;102:172-177.

25. Todd AC, Buchanan R, Carroll S, et al. Tibia lead levels and methodological uncertainty in 12-year old children. Environ Res. 2001;86:60-65.

26. Hu H, Rabinowitz MB, Smith DR. Bone lead as a biological marker in epidemiologic studies of chronic toxicity: conceptual paradigms. Environ Health Perspect. 1998;106:1-8.

27. Kim R, Aro A, Rotnitzky A, Amarasiriwardena $\mathrm{C}, \mathrm{Hu} \mathrm{H}$. K x-ray fluorescence measurements of bone lead concentration: the analysis of low-level data. Physics Med Biol. 1995;40:1475-1485.

28. Liang K-Y, Zeger SL. Longitudinal data analysis using generalized linear models. Biometrika. 1986;73:13-22.

29. Hu H, Watanabe H, Payton M, Korrick S, Rotnizky A. The relationship between bone lead and hemoglobin. JAMA. 1994; 272:1512-1517.

30. Romeo R, Aprea C, Boccalon P, Orsi D, Porcelli B, Sartorelli P. Serum erythropoietin and blood lead concentrations. Int Arch Occup Environ Health. 1996;69: 73-75.

31. Osterode W, Barnas U, Geissler K. Dose dependent reduction of erythroid progenitor cells and inappropriate erythropoietin response in exposure to lead: new aspects of anaemia induced by lead. Occup Environ Med. 1999;56:106-109.

32. Liebelt EL, Schonfeld D, Gallagher P. Elevated blood lead levels in children are associated with lower erythropoietin concentrations. J Pediatr. 1999;154:107109 